(Supporting information)

\title{
Understanding the Single Atom Doping Effects in Oxygen Reduction with Atomically Precise Metal Nanoclusters
}

\author{
Site $\mathrm{Li}^{\dagger, 1}$, Anantha V. Nagarajan ${ }^{\ddagger 1}$, Shuo Zhao ${ }^{\dagger}$, Giannis Mpourmpakis ${ }^{* *}$, Rongchao Jin ${ }^{\dagger *}$ \\ $\dagger$ Department of Chemistry, Carnegie Mellon University, Pittsburgh, Pennsylvania 15213, United States \\ $\$$ Department of Chemical Engineering, University of Pittsburgh, Pittsburgh, Pennsylvania 15261, United States \\ ${ }^{1}$ Contribute equally. \\ * Corresponding authors: \\ Rongchao Jin, Email: rongchao@andrew.cmu.edu \\ Giannis Mpourmpakis, Email: gmpourmp@ pitt.edu
}

\section{Experimental Section}

Synthesis of catalysts: The syntheses of atomically precise Ag NCs followed previous reports. ${ }^{1-3}$ In a typical synthesis of $\mathrm{Ag}_{25} \mathrm{NCs}, 37 \mathrm{mg}$ silver nitrate was dissolved in methanol followed by the addition of $90 \mu \mathrm{L}$ 2,4-dimethylbenzenethiolate dissolved in $\mathrm{CH}_{2} \mathrm{Cl}_{2}$. The mixture was stirred for $30 \mathrm{~min}$ followed by the addition of $7 \mathrm{mg} \mathrm{PPh}{ }_{4} \mathrm{Br}$. After that, aqueous $\mathrm{NaBH}_{4}$ solution was rapidly added to the mixture. The reaction was allowed to proceed overnight. The NCs were obtained after methanol wash. In the doping NCs, corresponding Au salt, Pd salt and Pt salt were added as the precursor.

Preparation of catalyst ink: NCs were loaded on carbon black by stirring with a mass ratio of $10 \%$. Then the ink can be obtained by mixing the carbon-loaded catalyst in isopropanol and ultrasonic mixing for $30 \mathrm{~min}$. The concentration of the catalytic ink was $2 \mathrm{mg} \mathrm{mL}^{-1}$.

Characterization: UV-vis spectra were acquired on a Hewlett-Packard Agilent 8453 diode array spectrophotometer at room temperature.

Electrochemical Measurements: The electrochemical measurements were carried out with a threeelectrode system on a CHI 620C electrochemical station. A glassy carbon (GC) RDE (PINE, $5 \mathrm{~mm}$ diameter, $0.196 \mathrm{~cm}^{2}$ ) was used as working electrode. A platinum wire and an $\mathrm{Ag} / \mathrm{AgCl}$ (saturated with $\mathrm{KCl}$ ) electrode were used as counter electrode and reference electrode, respectively. To prepare the working electrode, the GC electrode was polished and cleaned with ethanol. Then 5 $\mu \mathrm{L}$ as prepared ink was transferred on the GC working electrode, followed by $5 \mu \mathrm{L} 0.02 \mathrm{wt} \%$ Nafion. The electrolyte was degassed by bubbling into nitrogen for $30 \mathrm{~min}$ before electrochemical measurements and 0.1 M PBS $(\mathrm{pH}=6.8)$ was used as electrolyte. The ORR polarization curves were obtained by sweeping the potential from 0.2 to $-0.8 \mathrm{~V}$ versus $\mathrm{Ag} / \mathrm{AgCl}$ at room temperature at a scan rate of $20 \mathrm{mV} \mathrm{s}^{-1}$.

\section{Computational}

All DFT calculations were performed using the Perdrew-Burke-Ernzerhof (PBE) ${ }^{4}$ functional and the double zeta valence polarization $(\mathrm{DZVP})^{5}$ basis set in combination with Goedecker-Teter- 
Hutter $(\mathrm{GTH})^{6}$ pseudopotentials. The calculations were performed in the $\mathrm{CP} 2 \mathrm{~K}^{7}$ package with a cutoff of $500 \mathrm{Ry}$. This level of theory has been previously used to investigate the catalytic activity of Au-based catalysts ${ }^{8}$. The initial geometries of all the Ag nanoclusters (NCs) were obtained from reported crystal structures or experimentally-derived crystallographic data ${ }^{1,9}$. All thiolate groups were substituted with $-\mathrm{SCH}_{3}$ ligands, a simplification that has successfully captured trends related to the catalytic activity of $\mathrm{Au} \mathrm{NCs}$ while maintaining their structural integrity ${ }^{8,10-12}$. NCs were relaxed in a non-periodic cell of dimensions $30 \AA$ x $30 \AA$ x $30 \AA$ for all the Ag NCs until forces were less than $0.002 \mathrm{eV} \mathrm{A}^{-1}$. The box sizes were chosen based on the shape and size of the NCs to ensure enough vacuum space to obtain accurate ground state energies.

Free energies of ligand removal and $* \mathrm{OOH}$ adsorption was calculated per equation 1:

$$
\Delta G=\Delta E+\triangle Z P E+\int C_{p} d T-T S
$$

Where ZPE represents the Zero Point Energy, Cp (heat capacity), and S (entropy) terms and E, the electronic energy of each system. For constructing the ORR free energy diagram, the vibrational modes of only the adsorbate were factored into the free energy calculations. The frequencies of the adsorbate were calculated using the ideal gas rigid-rotor harmonic oscillator approximation. Gibbs free energies for ligand removal were obtained by calculating the vibrational modes of the entire nanocluster and then using equation (1). The computational hydrogen electrode $(\mathrm{CHE})^{13}$ was used to account for the free energy of the proton and an electron, i.e. $\mathrm{G}\left(\mathrm{H}^{+}+\mathrm{e}^{-}\right)=\mathrm{G}\left(1 / 2 \mathrm{H}_{2}\right)$. The energetics are reported at $0 \mathrm{~V}$ against the reversible hydrogen electrode (RHE).

Both $-\mathrm{CH}_{3}$ and $-\mathrm{SCH}_{3}$ removal were considered from the $\mathrm{Ag}$ NCs. The energy required to release $\mathrm{a}-\mathrm{CH}_{3}$ or $-\mathrm{SCH}_{3}$ group from the thiolate-protecting layer of the $\left[\mathrm{Ag}_{25}\left(\mathrm{SCH}_{3}\right)_{18}\right]^{-} \mathrm{NC}$ was treated as an electrochemical reduction step based on the following reactions:

$$
\begin{gathered}
\frac{1}{2} \mathrm{H}_{2}+\left[\mathrm{Ag}_{25}\left(\mathrm{SCH}_{3}\right)_{18}\right]^{-} \rightarrow\left[\mathrm{Ag}_{25} \mathrm{~S}\left(\mathrm{SCH}_{3}\right)_{17}\right]^{-}+\mathrm{CH}_{4} \\
\frac{1}{2} \mathrm{H}_{2}+\left[\mathrm{Ag}_{25}\left(\mathrm{SCH}_{3}\right)_{18}\right]^{-} \rightarrow\left[\mathrm{Ag}_{25}\left(\mathrm{SCH}_{3}\right)_{17}\right]^{-}+\mathrm{HSCH}_{3} \\
\Delta G=\Sigma G_{\text {products }}-\Sigma G_{\text {reactants }}
\end{gathered}
$$

Where $\mathrm{G}\left[\mathrm{H}_{2}\right], \mathrm{G}\left[\mathrm{Ag}_{25}\left(\mathrm{SCH}_{3}\right)_{18}\right]^{-}, \mathrm{G}\left[\mathrm{Ag}_{25}\left(\mathrm{SCH}_{3}\right)_{17}\right]^{-}, \mathrm{G}\left[\mathrm{HSCH}_{3}\right]$ are the gas phase free energies of molecular hydrogen, the fully protected $\mathrm{NC}$, the $\mathrm{NC}$ with a thiol $\left(-\mathrm{SCH}_{3}\right)$ group removed and the $\mathrm{HSCH}_{3}$ molecule. The free energy for ligand removal from the doped $\mathrm{Ag} \mathrm{NCs}$ was calculated using the same methodology (treating it as an electrochemical step). The $\mathrm{Ag}_{25}, \mathrm{Ag}_{24} \mathrm{Au}$ and $\mathrm{Au} \mathrm{NCs}$ possess a charge of -1 while the $\mathrm{Ag}_{24} \mathrm{Pt}$ and $\mathrm{Ag}_{24} \mathrm{Pd} \mathrm{NCs}$ have a charge of -2. In these reactions, a $-\mathrm{CH}_{3}$ (eq. (2)) or $-\mathrm{SCH}_{3}$ (eq. (3)) group is removed to generate an exposed sulfur or metal site on the NC surface, respectively.

Gibbs free energy diagrams were calculated for the proposed reaction pathways. Each reaction step, such as the free energy $(\Delta \mathrm{G})$ for the formation of the $\mathrm{OOH}^{*}$ intermediate, was calculated as follows:

$$
\Delta \mathrm{G}=\mathrm{G}\left[{ }^{*} \mathrm{OOH}\right]+1.5 \mathrm{G}\left[\mathrm{H}_{2}\right]-\mathrm{G}\left[{ }^{*}\right]-2 \mathrm{G}\left[\mathrm{H}_{2} \mathrm{O}\right]
$$

where $\mathrm{G}\left[{ }^{*} \mathrm{OOH}\right]$ is the free energy of the ${ }^{*} \mathrm{OOH}$ intermediate bound on the $\mathrm{NC}, \mathrm{G}\left[{ }^{*}\right]$ the free energy of the $\mathrm{NC}, \mathrm{G}\left[\mathrm{H}_{2}\right]$ the free energy of $\mathrm{H}_{2}$, and $\left.\mathrm{G}_{2} \mathrm{H}_{2} \mathrm{O}\right]$ the free energy of the $\mathrm{H}_{2} \mathrm{O}$ molecule. 
The final reaction free energies are adjusted by taking into account the $\mathrm{H}_{2} \mathrm{O}_{(\mathrm{l})} / \mathrm{H}_{2(\mathrm{~g})}$ reference and the equilibrium potential of $\mathrm{H}_{2} \mathrm{O}_{2(1)}$ formation of $-0.68 \mathrm{~V}^{14}$. Any imaginary (negative) vibrational modes obtained were less than $-50 \mathrm{~cm}^{-1}$ and were replaced with a frequency of $5 \mathrm{~cm}^{-1}$ and or 7.5 $\mathrm{cm}^{-1}$. These positive numbers were chosen based on the smallest positive frequencies observed in the calculations. This approach has minimal effect on the free energy of the NCs under consideration. Previous reports have discussed the effect of low lying frequencies and deemed them to also have minimal effect on free energies ${ }^{15-17}$.

\section{Supporting Figures and Tables}
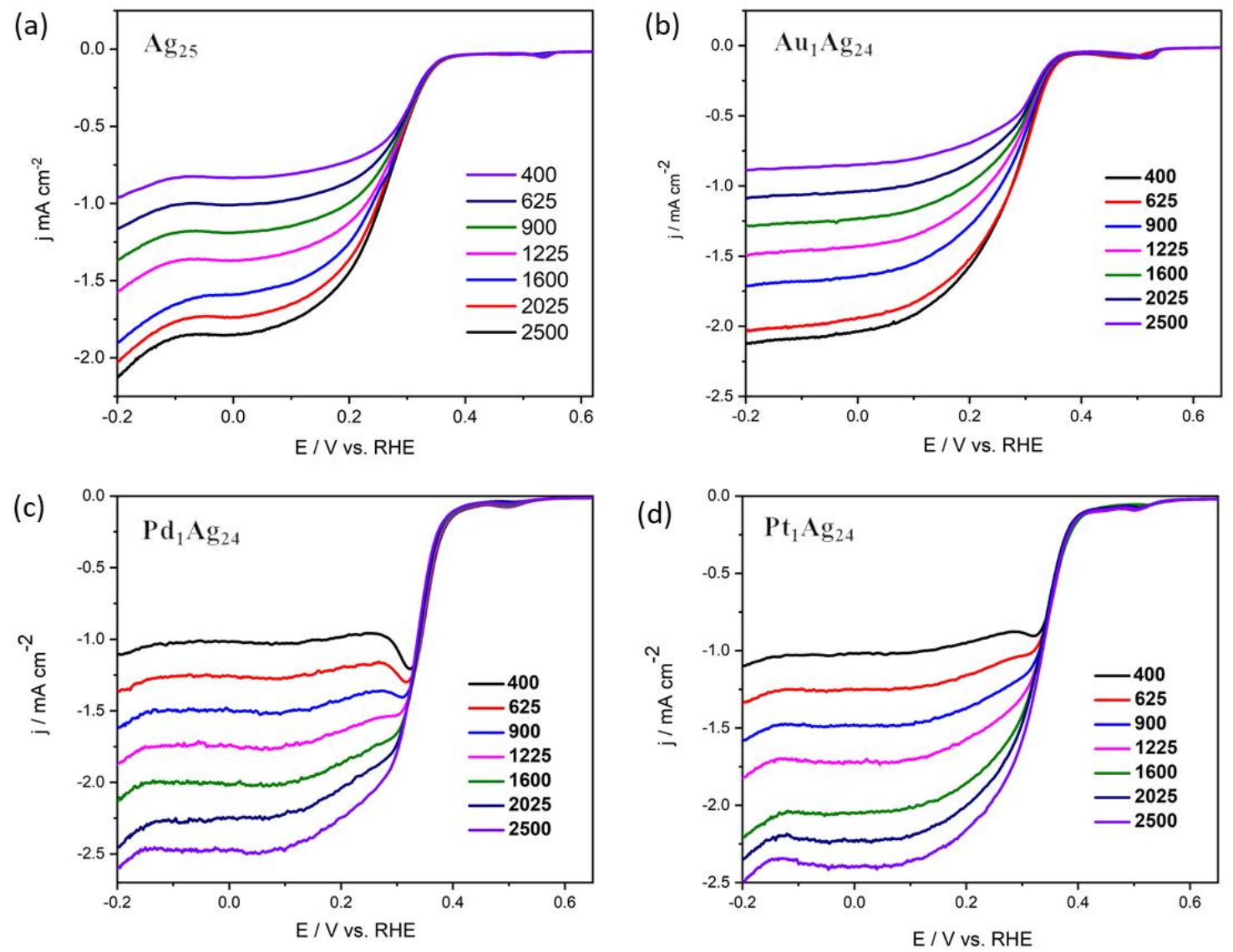

Fig. S1. RDE voltammograms at different rotating speeds: (a) $A g_{25}$, (b) $\mathrm{Au}_{1} \mathrm{Ag}_{24}$, (c) $\mathrm{Pd}_{1} \mathrm{Ag}_{24}$, (d) $\mathrm{Pt}_{1} \mathrm{Ag}_{24}$. 

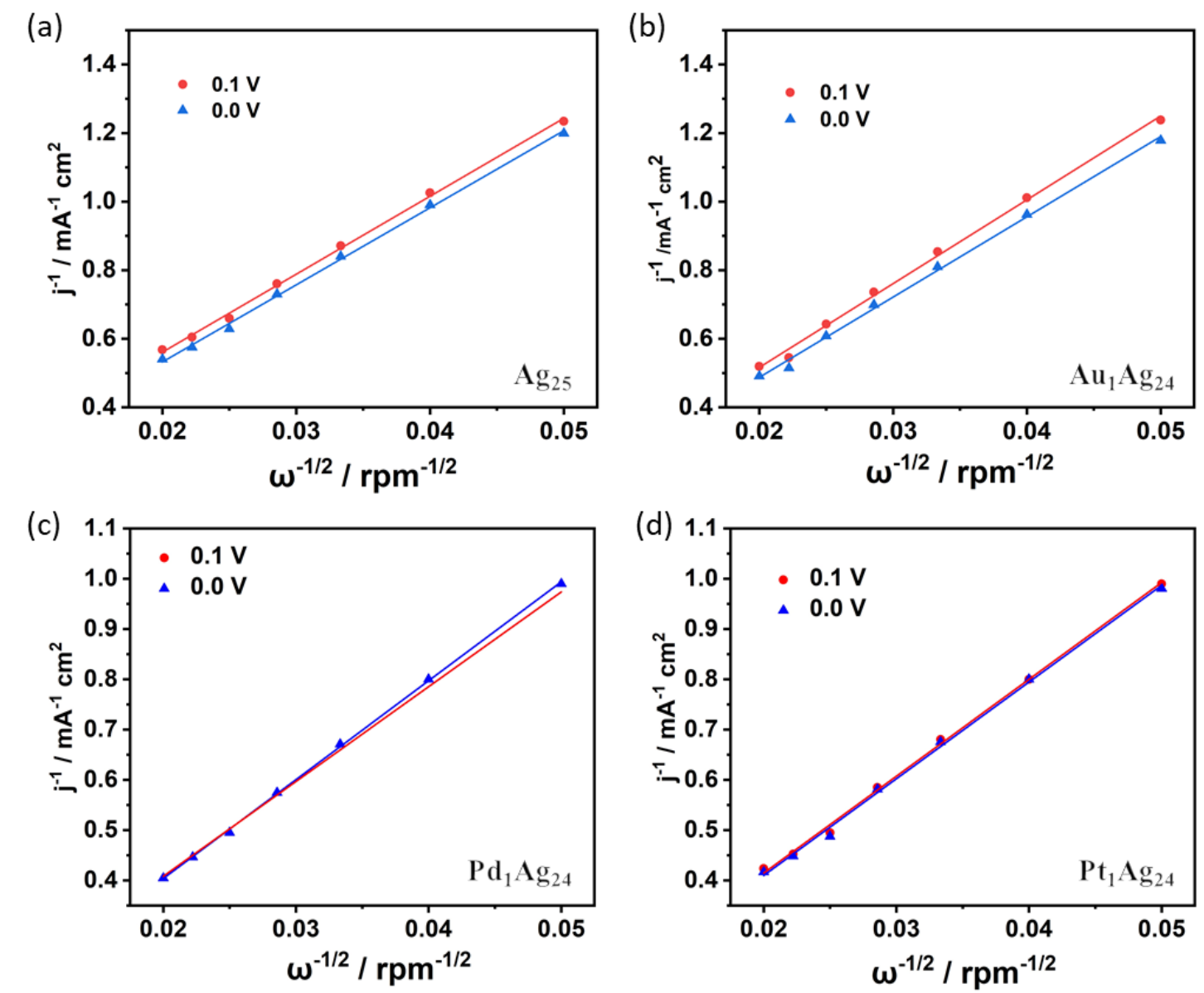

Fig. S2. Koutecky-Levich plots $\left(j^{-1}\right.$ vs. $\omega^{-1 / 2}$ ) of (a) $\operatorname{Ag}_{25}$, (b)Au $\operatorname{Au}_{1} \mathrm{Ag}_{24}$, (c) $\operatorname{Pd}_{1} \mathrm{Ag}_{24}$, (d) $\mathrm{Pt}_{1} \mathrm{Ag}_{24 .}$

Note: To further investigate the ORR process, rotating disk electrode (RDE) voltammograms for all 4 samples were obtained at different rotating speeds from 400 to $2500 \mathrm{rpm}$ (Fig. S1). The corresponding Koutecky-Levich plots $\left(j^{-1}\right.$ vs. $\omega^{-1 / 2}, j$ represents the current density and $\omega$ the rotation speed) were constructed to develop further mechanistic insight (Fig. S2). Specifically, the number of electrons transferred in the ORR process can be calculated using the K-L equations:

$$
\begin{aligned}
& \frac{1}{j}=\frac{1}{j_{d}}+\frac{1}{j_{k}}=\frac{1}{B \omega^{1 / 2}}+\frac{1}{j_{k}} \\
& \mathrm{~B}=0.62 \mathrm{nF} C_{0} D_{0}^{2 / 3} \eta^{-1 / 6}
\end{aligned}
$$

Where $\mathrm{j}$ stands for the current density, $\mathrm{j}_{\mathrm{k}}$ the kinetic current density, $\mathrm{j}_{\mathrm{d}}$ the diffusion-limited current density, $\omega$ the rotating speed RDE, $n$ the number of electrons transferred in the ORR process, $\mathrm{F}$ the Faraday constant, $\mathrm{C}_{0}$ the concentration of $\mathrm{O}_{2}$ in the electrolyte, $\mathrm{D}_{0}$ the diffusion coefficient of $\mathrm{O}_{2}$, and $\eta$ the viscosity of the electrolyte. The number of electrons transferred in the ORR process can be obtained using the slope of K-L equations (1/B). 


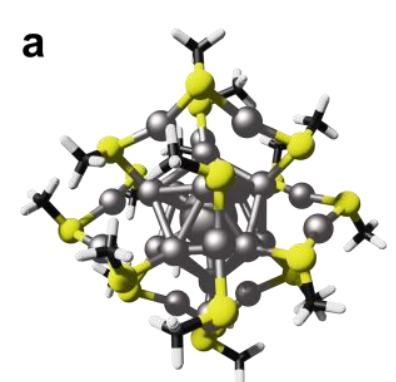

$\mathrm{Ag}_{25}$

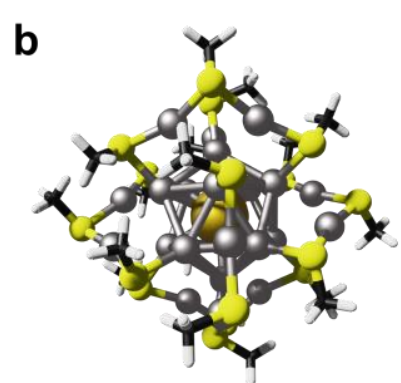

$\mathrm{Au}_{1} \mathrm{Ag}_{24}$

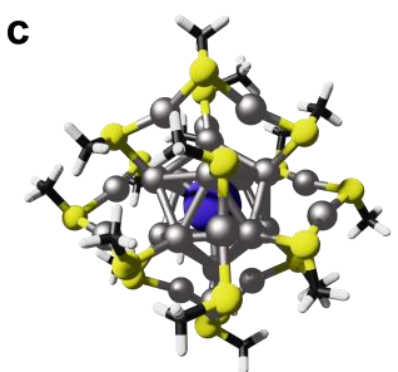

$\mathrm{Pt}_{1} \mathrm{Ag}_{24}$

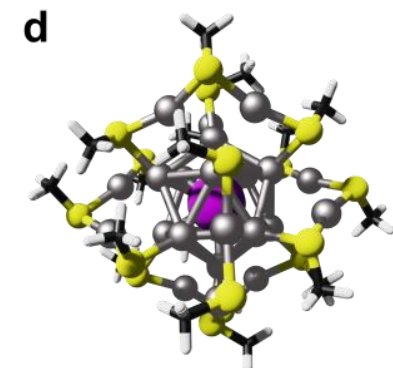

$\mathrm{Pd}_{1} \mathrm{Ag}_{24}$

Fig. S3. Relaxed structures of the NCs: a. $\left[\mathrm{Ag}_{25}\left(\mathrm{SCH}_{3}\right)_{18}\right]^{-}$, b. $\left[\mathrm{Au}_{1} \mathrm{Ag}_{24}\left(\mathrm{SCH}_{3}\right)_{18}\right]^{-}$, c. $\left[\mathrm{Pd}_{1} \mathrm{Ag}_{24}\right.$ $\left.\left(\mathrm{SCH}_{3}\right)_{18}\right]^{2-}$, d. $\left[\mathrm{Pt}_{1} \mathrm{Ag}_{24}\left(\mathrm{SCH}_{3}\right)_{18}\right]^{2-}$. Grey spheres indicate $\mathrm{Ag}$; yellow, $\mathrm{S}$; black, C; white, hydrogen; gold, Au; pink, Pd; blue, Pt. 
a

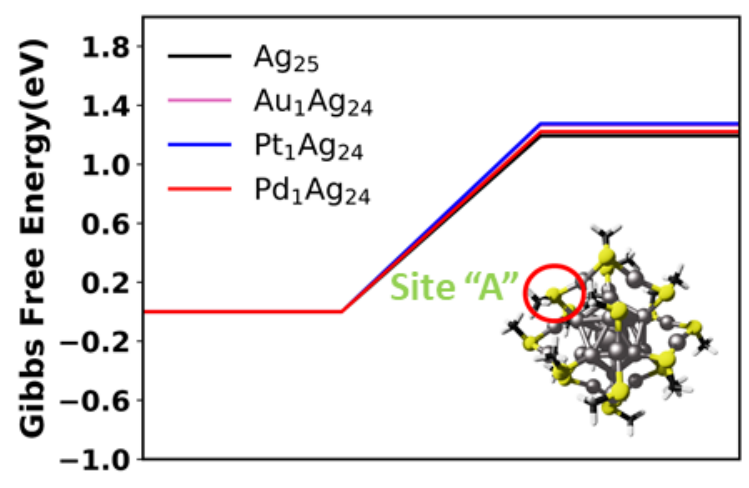

C

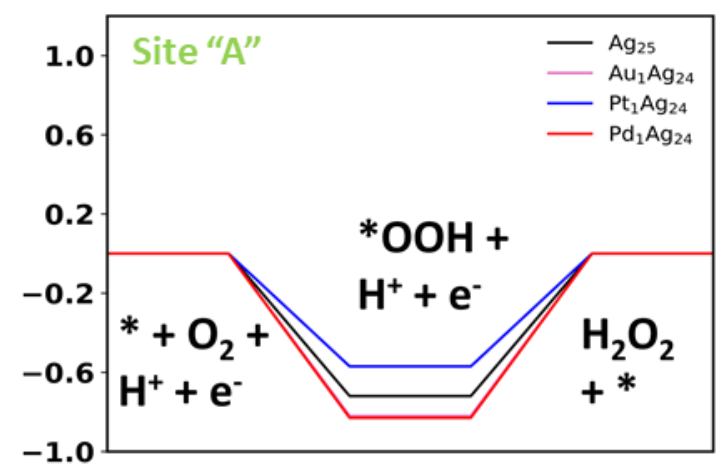

b

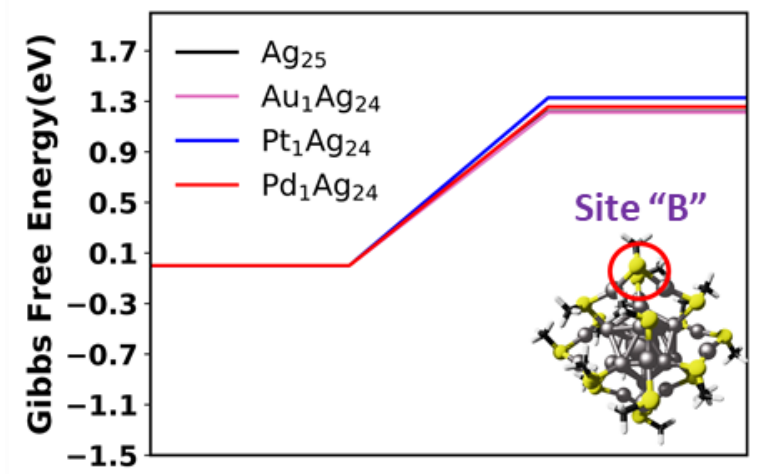

d

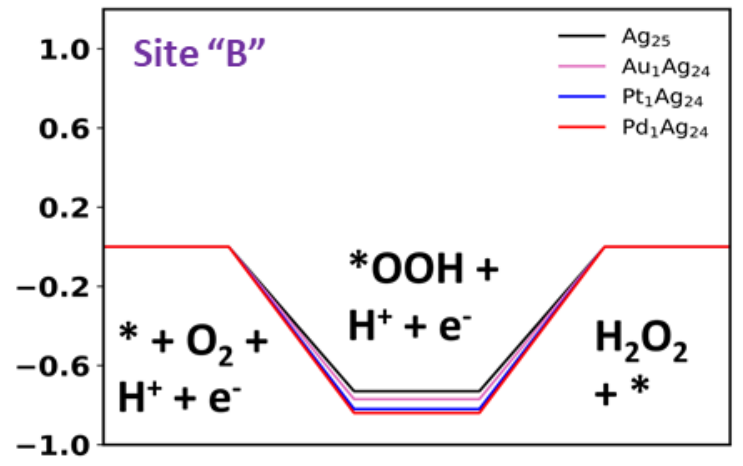

Fig. S4. Ligand removal energetics for -SR removal from (a) site 'A' and (b) site 'B' and ORR pathway on the respective (c) site 'A' and (d) site 'B' on the NCs with -SR removed. Red circles denote site of ligand removal. Solid lines represent the free energy at $0 \mathrm{~V}$ vs RHE. 


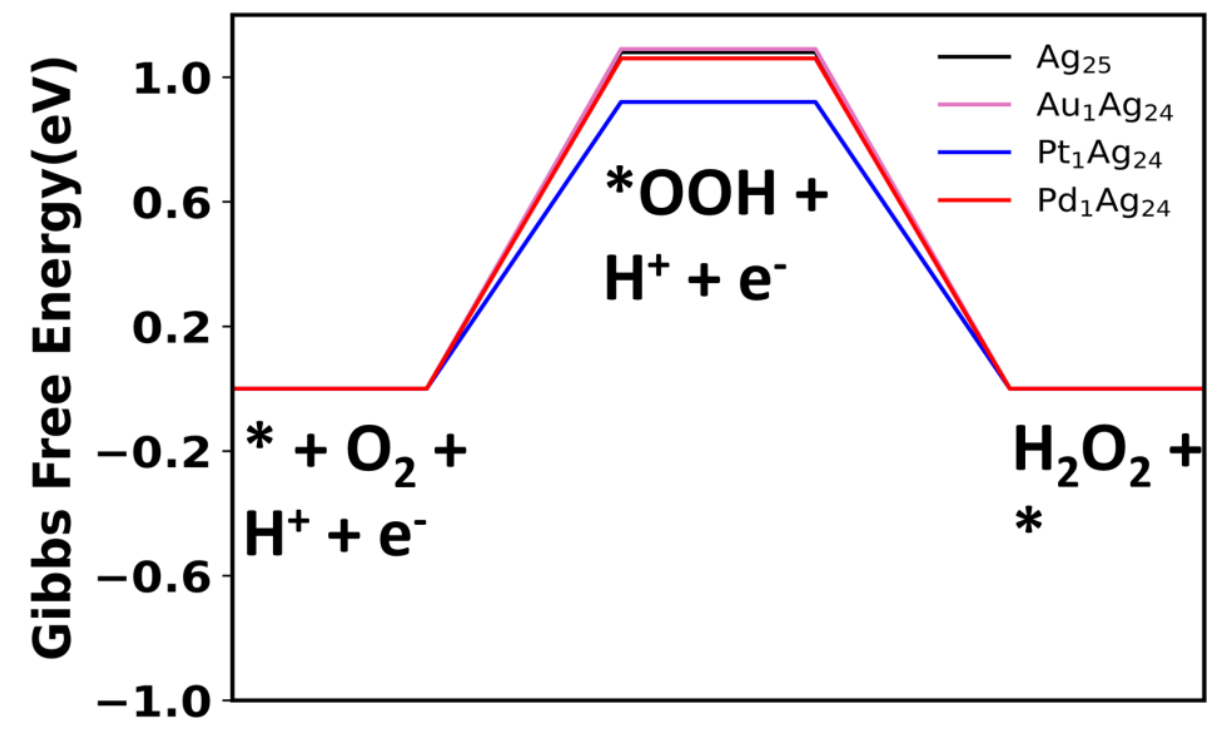

Fig. S5. Free energy diagram for ORR on fully protected Ag NCs. Solid lines represent the free energy at $0 \mathrm{~V}$ vs RHE. 

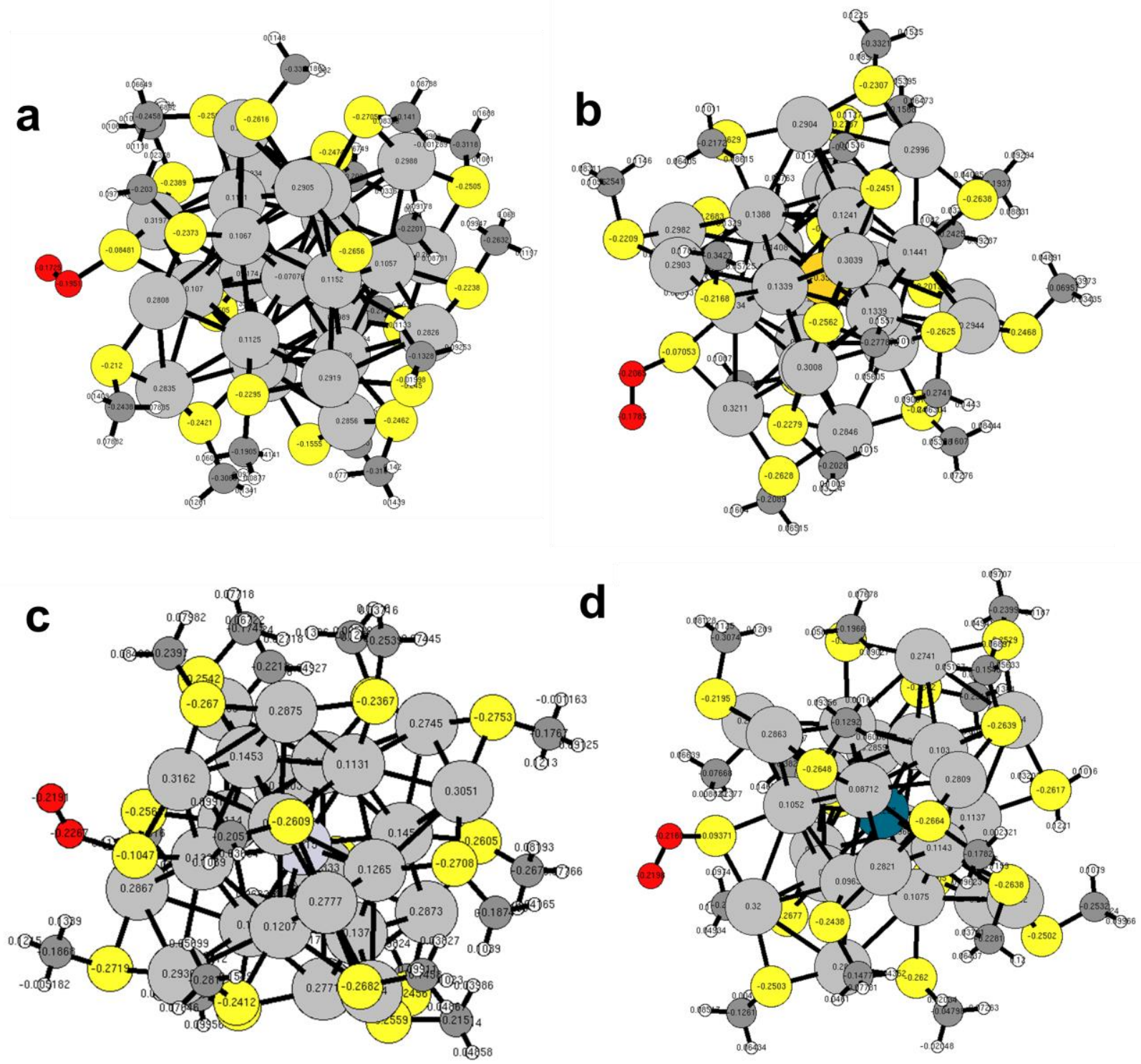

Fig. S6. Bader charge analysis on the NCs. (a) $\mathrm{Ag}_{25} \mathrm{~S}\left(\mathrm{SCH}_{3}\right)_{17}{ }^{1-}$, (b) $\mathrm{Au}_{1} \mathrm{Ag}_{24} \mathrm{~S}\left(\mathrm{SCH}_{3}\right)_{17}{ }^{1-}$, (c) $\mathrm{Pd}_{1} \mathrm{Ag}_{24} \mathrm{~S}\left(\mathrm{SCH}_{3}\right)_{17}{ }^{2-}$, (d) $\mathrm{Pt}_{1} \mathrm{Ag}_{24} \mathrm{~S}\left(\mathrm{SCH}_{3}\right)_{17}{ }^{2-}$. Red circle encloses the oxygen atoms present on the metal atom (-R removed $\mathrm{NC}$ on site $\mathrm{A})$.

Note: The total charge on oxygen on each of the NCs is given below:

\begin{tabular}{|l|l|}
\hline $\mathrm{NC}$ & Charge on $\mathrm{O}_{2}$ \\
\hline$\left[\mathrm{Ag}_{25} \mathrm{~S}\left(\mathrm{SCH}_{3}\right)_{17}\right]^{1-}$ & -0.38 \\
\hline$\left[\mathrm{Au}_{1} \mathrm{Ag}_{24} \mathrm{~S}_{\left.\left(\mathrm{SCH}_{3}\right)_{17}\right]^{1-}}\right.$ & -0.39 \\
\hline$\left[\mathrm{Pt}_{1} \mathrm{Ag}_{24} \mathrm{~S}\left(\mathrm{SCH}_{3}\right)_{17}\right]^{2-}$ & -0.44 \\
\hline$\left[\mathrm{Pd}_{1} \mathrm{Ag}_{24} \mathrm{~S}_{\left.\left(\mathrm{SCH}_{3}\right)_{17}\right]^{2-}}\right.$ & -0.45 \\
\hline
\end{tabular}

We observe greater negative charge on the $\mathrm{Pt}_{1} \mathrm{Ag}_{24}$ and $\mathrm{Pd}_{1} \mathrm{Ag}_{24} \mathrm{NCs}$, suggesting enhanced interaction of oxygen with these two NCs. 


\section{$\underline{\text { References }}$}

1. C. P. Joshi, M. S. Bootharaju, M. J. Alhilaly and O. M. Bakr, J. Am. Chem. Soc., 2015, 137, 11578-11581.

2. J. Yan, H. Su, H. Yang, S. Malola, S. Lin, H. Häkkinen and N. Zheng, J. Am. Chem. Soc., 2015, 137, 11880-11883.

3. X. Kang, S. Chen, S. Jin, Y. Song, Y. Xu, H. Yu, H. Sheng and M. Zhu, ChemElectroChem, 2016, 3, 1261-1265.

4. J. P. Perdew, K. Burke and M. Ernzerhof, Phys. Rev. Lett., 1996, 77, 3865-3868.

5. J. VandeVondele and J. Hutter, J. Chem. Phys., 2007, 127, 114105.

6. S. Goedecker, M. Teter and J. Hutter, Phys. Rev. B, 1996, 54, 1703-1710.

7. J. VandeVondele, M. Krack, F. Mohamed, M. Parrinello, T. Chassaing and J. Hutter, Comput. Phys. Commun., 2005, 167, 103-128.

8. N. Austin, S. Zhao, J. R. McKone, R. Jin and G. Mpourmpakis, Catal. Sci. Technol., 2018, 8, 3795-3805.

9. A. Das, T. Li, K. Nobusada, C. Zeng, N. L. Rosi and R. Jin, J. Am. Chem. Soc., 2013, 135, 18264-18267.

10. D. R. Kauffman, D. Alfonso, C. Matranga, P. Ohodnicki, X. Deng, R. C. Siva, C. Zeng and R. Jin, Chem. Sci., 2014, 5, 3151-3157.

11. G. Li, H. Abroshan, Y. Chen, R. Jin and H. J. Kim, J. Am. Chem. Soc., 2015, 137, $14295-$ 14304.

12. G. Li, H. Abroshan, C. Liu, S. Zhuo, Z. Li, Y. Xie, H. J. Kim, N. L. Rosi and R. Jin, ACS Nano, 2016, 10, 7998-8005.

13. J. K. Nørskov, J. Rossmeisl, A. Logadottir, L. Lindqvist, J. R. Kitchin, T. Bligaard and H. Jónsson, J. Phys. Chem. B., 2004, 108, 17886-17892.

14. F. Sun, C. Deng, S. Tian and Q. Tang, ACS Catalysis, 2021, 11, 7957-7969.

15. J. Elm, J. Phys. Chem. A., 2017, 121, 8288-8295.

16. I. M. Alecu, J. Zheng, Y. Zhao and D. G. Truhlar, J. Chem. Theory Comput., 2010, 6, 2872-2887.

17. N. Myllys, J. Elm and T. Kurtén, Comput Theor Chem., 2016, 1098, 1-12. 